\title{
Postnatal care coverage and its determinants in Sri Lanka: analysis of the 2016 demographic and health survey
}

Upuli Amaranganie Pushpakumari Perera ${ }^{1,2^{*}}$, Yibeltal Assefa ${ }^{2}$ and Uttara Amilani ${ }^{1}$

\begin{abstract}
Background: Postnatal care (PNC) is important for preventing morbidity and mortality in mothers and newborns. Even though its importance is highlighted, PNC received less attention than antenatal care. This study determines the level of PNC coverage and its determinants in Srilanka.

Methods: This is a secondary analysis of the 2016 Demographic and Health Survey. Receiving full postnatal care (FPNC) was defined with a set of indicators to detect adequate care for mother and newborn. Demographic and socioeconomic associated factors for receiving FPNC were identified using binary and multiple logistic regression. Variables that had marginal relationship with receiving FPNC which $p$-value less than or equal to 0.2 at binary analysis were selected and included in the multiple logistic regression models. We used manual backward stepwise regression to identify variables which had independent association with receiving FPNC on the basis of adjusted odds ratios (AOR), with 95\% confidence interval (Cl) and p-value less than 0.05. All analyses were performed in SPSS 25.

Results: Of the 8313 women with a live birth in the last 5 years, more than $98 \%$ had received postnatal care at facility at least $24 \mathrm{~h}$. More than three-fourth of mothers $(n=5104)$ received the FPNC according to WHO guideline. Four factors were positively associated with receiving FPNC: mothers received antenatal home visits by Public health midwife ( $A O R=1.98,95 \% \mathrm{Cl} 1.65-2.39$ ), mothers who got information about antenatal complications and places to go at antenatal clinics (AOR $=1.56,95 \% \mathrm{Cl} 1.27-1.92)$, been Sinhala (AOR $=1.89,95 \% \mathrm{Cl} 1.35-2.66)$ and having own mobile phone $(A O R=1.19,95 \% \mathrm{Cl} 1.02-1.38)$. Mothers who are residing in rural area $(A O R=0.69795 \% \mathrm{Cl}=0.52-0.93]$ compared to those who reside in urban areas and maternal age between 20 and 34 years [AOR $=0.72,95 \% \mathrm{Cl} 0.54$ 0.97] compared to maternal age less than 20 years were detected as negatively associated.
\end{abstract}

Conclusion: Receiving FPNC in Srilanka is high. However, inequity remains to be a challenge. Socio-demographic factors are associated with FPNC coverage. Strategies that aim to improve postnatal care should target improvement of non-health factors as well.

Keywords: FPNC, Demographic and health survey, Socio-demographic factors

\footnotetext{
* Correspondence: tauapp100@gmail.com

${ }^{1}$ Ministry of Health, Colombo, Sri Lanka

${ }^{2}$ The University of Queensland, Brisbane, Australia
}

(c) The Author(s). 2021 Open Access This article is licensed under a Creative Commons Attribution 4.0 International License, which permits use, sharing, adaptation, distribution and reproduction in any medium or format, as long as you give appropriate credit to the original author(s) and the source, provide a link to the Creative Commons licence, and indicate if changes were made. The images or other third party material in this article are included in the article's Creative Commons licence, unless indicated otherwise in a credit line to the material. If material is not included in the article's Creative Commons licence and your intended use is not permitted by statutory regulation or exceeds the permitted use, you will need to obtain permission directly from the copyright holder. To view a copy of this licence, visit http://creativecommons.org/licenses/by/4.0/. The Creative Commons Public Domain Dedication waiver (http://creativecommons.org/publicdomain/zero/1.0/) applies to the data made available in this article, unless otherwise stated in a credit line to the data. 


\section{Background}

The postnatal (PN) period begins immediately after the birth of the baby and extends up to 42 days after birth [1]. It consists of immediate (covers the first $24 \mathrm{~h}$ from birth), early (from Days 2 through 7), and late (from Days 8 through 42) periods for the purposes of describing care provision. Close direct or indirect supervision by a skilled attendant is required in the immediate period when the risks are highest More than $60 \%$ of global maternal deaths occur during the PN period [1]. According to a review, $45 \%$ of postpartum maternal deaths occur within 1 day of delivery; approximately $65 \%$ occur within 1 week and roughly $80 \%$ occur within 2 weeks [2]. High levels of maternal mortality is detected in all three periods; antepartum, intra-partum and postpartum in Sub-Saharan African (SSA) countries [3]. Globally, 2.4 million neonates died in 2019, around one million within first $24 \mathrm{~h}$ of life. The vast majority occurred in lower and middle income countries (LMIC) [4]. Hence, postnatal care (PNC) for the women and the child is important in detecting and treating complications that occur during the delivery as well as providing information for the mother on her and her newborn health. Even though the PNC period is associated with risk, it is the most neglected period for the provision of quality care. Less attention was given for PN period in developing countries [5-8]. Postnatal care utilization in SSA countries was around 52\% ranging from 31 to $73 \%$ according to DHS survey analysis from 2006 to 2018 in 36 SSA countries [9]. Receiving a PN check ranged from 26 to $94 \%$ in SSA countries [5]. Only half of Ugandan postpartum women attended PNC services within 2 days of childbirth [6]. In Myanmar, only around a quarter has received PNC, 4 checkups in postpartum period [7]. According to the most recent country-level data, an average of $62 \%$ of women, ranging from 16 to $100 \%$, around the world attends PN visits. PN visits for neonates are on average 36\% ranging from 4 to $100 \%$ [8]. Even though with the increase in facility delivery, few women and newborn stay in the facility for the recommended $24 \mathrm{~h}$ after birth [4].

To help countries improve the situation, the World Health Organization (WHO) provided recommendations on how a mother who has just delivered should be treated. It recommends receiving first PN contact within the immediate PN period. In addition to that, minimum three additional PN checkups are recommended. It further recommends at least $24 \mathrm{~h}$ facility care for healthy mother and newborn. Home visits for mother and baby are also recommended [10]. Countries develop their national guidelines for the improvement of PNC based on the WHO's recommendation [11-13]. In SriLanka, Family Health Bureau (FHB), focal point for maternal and childcare has updated the PNC in 2011 in its maternal care package [11]. It clearly describes how to provide quality hospital and field care for PN mothers and newborns. According to maternal discharging policy in Sri Lanka, immediate PNC during is given at a hospital. Once the mother is discharged from the hospital, professional $\mathrm{PNC}$ is provided through home visits by the Public health midwife (PHM) and PN clinics conducted by Medical officers of Health $(\mathrm{MOOH})$ [11].

Maternal and neonatal health $(\mathrm{MNH})$ of SriLanka is a part of the reproductive, maternal, neonatal, child, adolescence and youth healthcare programme, which has been evolved over many decades. Family Health Bureau is the focal point for planning, implementation, monitoring and evaluation of MNH. Services are supplied by preventive and curative health systems at provincial and district level [14]. Sri Lanka has achieved a remarkably better maternal health status despite its weak economic status [15]. Investments into human development such as free education and free health care have contributed significantly to these achievements [16, 17]. More than 99\% of pregnant mothers are receiving antenatal care, institutional delivery and immediate PNC in institutions [16]. Quality of PNC received at institutions has been assessed with different studies and found satisfactory according to clients $[18,19]$. There is very little information regarding the receiving various aspects of postnatal care for mothers and newborns such as institutional care, time of receiving care, home visit care according to above mentioned guidelines. There is also paucity of research to determine the determinants of receiving PNC among mothers in SriLanka. Therefore the objective of this study is to determine the level of PNC coverage and its determinants in SriLanka.

\section{Methods}

\section{Data source}

We used data from the Sri Lanka Demographic and Health Survey (SLDHS) 2016. Sri Lanka constitutes 25 administrative districts within nine provinces. The SLDHS 2016 covered all 25 districts including the Northern Province, which was excluded in early surveys due to the civil war there [20].

\section{Sampling}

The sampling technique used to select respondents in SLDHS was two- stage stratified cluster sampling design. The sampling frame consisted of census blocks, the subdivision of a Grama niladhari division which is the smallest administration unit at village level. At the first stage, 2500 census blocks were selected as primary sampling units (PSU). At the second stage, 12 housing units were selected from each selected PSU as the secondary sampling unit from all strata except from the strata of the districts in Western Province. In these districts, 10 
housing units were selected from each selected PSU. Totally, 28,800 housing units were selected for the survey. The detail of sampling is provided in the freely available SLDHS report [20].

Within the households, 18,510 married women aged 15-49 years were selected for interview and 18,302 interviewed with $98.9 \%$ response rate. SLDHS 2016 used computer assisted personal interview first time in the history of the Department of Census and Statistics (DCS) for field data collection. Trained data collecting officers collected detailed data on mothers' reproductive health behaviours and birth details of children with socioeconomic and demographic data. The dataset obtained from the DCS included 18,302 ever-married women. The current analysis included mothers of 8313 children born between 2011 and 2016. We assessed PNC separately in accordance to $\mathrm{WHO}$ guideline and Srilanka guidelines developed by FHB.

\section{Outcome variables}

Women those who have received full postnatal care (FPNC) in their PN period who delivered between 2011 and 2016 were considered as outcome variable. The outcome variable was recoded as a binary variable (yes/no) in the merged dataset. Receiving FPNC was defined with a set of indicators to detect adequate care for mother and newborn.

Composite score for receiving WHO FPNC was developed using following indicators

1. Had postpartum hospital stay more than $24 \mathrm{~h}$

2. Received PN check-up within $24 \mathrm{~h}$

3. Had additional 3 check-ups within 6 weeks of delivery.

This additional three may be in field or clinic setup. Therefore two different data; at least three PHM PN home visits irrespective of PN clinic visits or at least two PHM home visits with a PN clinic visit were used to calculate this indicator.

Another composite score for PNC guided by FHB was developed using following indicators which have been collected data in SLDHS 2016.

1. Had postpartum hospital stays more than $24 \mathrm{~h}$

2. Received PN check-up within $24 \mathrm{~h}$

3. Had a checkup by a doctor before discharge

4. Received a home visit by PHM before 5 days after delivery

5. Received at least four PN home visits by PHM within 6 weeks of delivery

6. Attended a PN clinic.

Both composite indicators took the value of 1 if all the above conditions are met.

\section{Independent variables}

A set of socio-demographic, economic and obstetric care factors which related to the receiving FPNC was used as independent variables. Socio-demographic characteristics were place of residence (urban, rural, estate) including province and district, religion (Buddhist and non-Buddhist) and ethnicity (Sinhala and non-Sinhala), maternal age at delivery(20 to 34 and below 20 / above 35), education status of mother and father (AL / above AL and up to pass $\mathrm{OL}$ ), occupation status of mother and father (occupied or not), birth order (first born and others) and sex of the child (male or female), involvement of the mother with healthcare decisions and other house-hold decisions, frequency of reading newspapers, listening to radio and watching television of mothers, ownership of mobile phone and bank account of mother and Wealth Index (WI) (richer/ richest and medium/poorer/poorest). Included obstetric care related factors were the details in antenatal care and delivery. Antenatal registration by PHM (yes or no), antenatal clinics attendance (yes or no), antenatal clinic frequency ( 4 or more and less than 4), antenatal clinic made awareness on complication and services (yes or no), antenatal home visits by PHM (yes or no), place of delivery (institution and non-institution) and mode of delivery (vaginal or other) were used.

\section{Measuring socio-economic status}

WI and quintile were constructed to represent household economy using the available wealth variables such as housing materials, water source, type of latrines, availability of electricity, and ownership of durable consumer items such as radio, television, mobile phone, land phone, refrigerator, bicycle, motorcycle etc. Principal component and factor analysis statistical method was used to calculate the WI [21].

\section{Data analysis}

Data were analyzed with SPSS version 25. Basic sociodemographic characteristics of the study sample were presented as descriptive data in frequency and percentages. PN care indicators and prevalence of receiving FPNC according to $\mathrm{WHO}$ guideline and FHB guidelines were presented separately as number and percentages.

Associated factors for receiving WHO FPNC were identified using binary and multiple logistic regression (MLR) tests. Variables that had marginal relationship with receiving FPNC which $p$-value less than or equal to 0.2 at binary analysis were selected in to MLR models for controlling the possible effect of confounders. We used manual backward stepwise regression to identify variables which had independent association with receiving WHO FPNC on the basis of adjusted odds ratios (AOR), with $95 \% \mathrm{CI}$ and $p$-value less than 0.05 . 


\section{Results}

\section{Background characteristics}

A total of 18,302 ever married women of reproductive age, were included in the SLDHS 2016. Of those, only 8313 women who had their last birth in the 5 years preceding the survey were analyzed here. The overall characteristics of study population are tabulated in Table 1 . The majority $(78 \%, n=5523)$ of the mothers were residing in rural areas, were belong to 20 to 34 years age group $(75 \%, n=5372)$ and were non-working (77\%, $n=5535)$. Most of them were involving healthcare decisions $(85 \%, n=6136)$ and other household decisions (76.1\%, $n=5472)$. Almost all $(99.6 \%, n=8276)$ were delivered at institutions. Majority had registered with PHM (99\%, $n=7047)$, had antenatal clinic visits (99\%, $n=7118)$ and received antenatal home visits by PHM $(90.6 \%, n=6510)$.

\section{Postnatal care coverage}

Vast majority (>98\%) of postnatal mothers had received postnatal care at facility at least $24 \mathrm{~h}$. More than $95 \%$ of mothers received home care by PHM. Relatively low coverage were detected in home visit by PHM within 5 days $(59 \%, n=3935)$ and receiving at least four postpartum home visits by PHM $(26 \%, n=1712)$. Around $78 \%$ $(n=5606)$ of mothers attended postnatal clinic conducted by $\mathrm{MOOH}$, and less than $80 \%(n=4410)$ of them were examined by a doctor (Table 2 ).

More than three fourth of mothers $(76.9 \%, n=5104)$ received the FPNC according to $\mathrm{WHO}$ guideline while only $13.8 \%(n=860)$ received FPNC according to FHB guideline. FPNC received within the institution was 95.2\% $(n=7264)$ while the field related care part was $14.3 \% \quad(n=926)$ according to the FHB guidelines (Table 2).

\section{Determinants of receiving FPNC}

Determinants of receiving FPNC according to WHO guideline were presented in Tables 3 and 4 as Crude OR and AOR respectively. In MLR model, mothers who received antenatal home visits by PHM were 1.99 (AOR = $1.99,95 \%$ CI $1.65-2.39, P<0.001)$ times more likely to receive FPNC than those without antenatal PHM home visits. Similarly, mothers who got information about antenatal complications and places to go at antenatal clinic $(\mathrm{ANC})$ were 1.56 times $(\mathrm{AOR}=1.56$, 95\% CI $1.27-$ $1.92, \mathrm{P}<0.001)$ more likely to receive FPNC than who did not. Mothers ethnicity, been Sinhala, major nationality in SriLanka $(\mathrm{AOR}=1.89,96 \%$ CI $1.35-2.66, P<0.001)$ and, having own mobile phone $(\mathrm{AOR}=1.19,95 \% \mathrm{CI}$ $1.02-1.38, P=0.027)$ were other factors which are significantly associated with receiving FPNC.

Mothers who are residing in rural area were 0.7 $[\mathrm{AOR}=0.697,95 \% \mathrm{CI}=0.52-0.93, P=0.015]$ times less likely to receive FPNC than those who reside in urban areas. Similarly, maternal age between 20 and 34 years were 0.72 less likely to have FPNC [AOR $=0.72,95 \% \mathrm{CI}$ 0.54-0.97, $P=0.029$ ] than mothers age less than 20 years. Maternal age with more than 35 years old were 0.85 times $[\mathrm{AOR}=0.85,95 \% \mathrm{CI} 0.72-1.003, P=0.054$ ] less likely to receive FPNC than those with less than 20 even though it was marginally significant.

Mother's socio-demographic factors such as being Buddhist $(\mathrm{OR}=1.65,95 \% \mathrm{CI}=1.47-1.86)$ than being Non Buddhist, higher maternal education with Advanced level and above $(\mathrm{OR}=1.16,95 \% \mathrm{CI}=1.03-1.31)$ than Ordinary level and below, household WI being in richer and richest $(\mathrm{OR}=1.19,95 \% \mathrm{CI}=1.06-1.36)$ than, poorest, poorer and middle and mothers having own bank account $(\mathrm{OR}=1.26,95 \% \mathrm{CI}=1.09-1.45)$ than not having showed positive association in univariate analysis. Likewise having more than 4 ANC visits $(\mathrm{OR}=2.34,95 \%$ $\mathrm{CI}=1.18-4.65)$ showed positive and normal vaginal delivery $(\mathrm{OR}=0.85,95 \% \mathrm{CI}=0.75-0.97)$ showed negative association in univariate analysis.

\section{Discussion}

The current analysis of SLDHS 2016 data revealed that nearly all mothers received timely PNC in an institution. More than three fourth $(76.9 \%)$ of postnatal mothers have received FPNC as recommended by WHO. Results from the MLR analysis indicate the following factors as positively associated with receiving FPNC. Receiving antenatal home visits by PHM, receiving knowledge about antenatal complications and available services in ANC, mothers having own mobile phone and belongs to Sinhala nationality. Likewise, it was found that being in rural area and older maternal age were negatively associated with receiving FPNC.

Almost all mothers receiving timely $\mathrm{PNC}$ in an institution reflects the achievements of maternity care in Sri Lanka within the existing free health services. In the field, majority received PHM home visits. Postnatal care indicators recommended by $\mathrm{FHB}$, which related to field activities such as PN home visits within 5 days of delivery and at least four home visits in PN period noticed relatively low values here. They were compatible with data derived from the field [14, 22, 23].

In Sri Lanka, PN home visits are done by highly trained PHMM. Lack of adequate number of competent healthcare workers, especially PHM, who is the grass root level caretaker of mothers and children in the field, may be the reason for receiving less than recommended home visits. Recommended number of PHMM, which is one per 3000 population hardly achieved in highly populated areas [24]. There are large numbers of vacancies in difficult geographical areas. Carrier as PHM in SriLanka becoming unpopulated among younger generation due 
Table 1 Basic socio-demographic characteristics of mothers' with children 0-5 years of age, Sri Lanka 2016/2017 $(n=8313)$

\begin{tabular}{lll}
\hline Characteristic & Number & Percentage \\
\hline Residence $(n=7077)$ & & \\
Urban & 1114 & 15.7 \\
Rural & 5523 & 78.0 \\
Estate & 440 & 6.2
\end{tabular}

Province

Western
Central
Southern
Northern
Eastern
North western
North central
Uva
Sabaragamuwa

\section{District}

Colombo
Gampaha
Kalutara
Kandy
Matale
Nuwaraeliya
Galle
Matara
Hambantota
Jaffna
Mannar
Vavuniya
Mulathive
Kilinochchi
Batticaloa
Ampara
Trincomalee
Kurunagala
Puttlam
Anuradhapura
Polonnaruwa
Badulla
Monaragala
Rathnapura
kegalle
Mam

Religion $(n=7077)$

Buddhist

$\begin{array}{ll}1545 & 18.6 \\ 1061 & 12.8 \\ 980 & 11.8 \\ 1011 & 12.2 \\ 931 & 11.2 \\ 887 & 10.7 \\ 556 & 6.7 \\ 594 & 7.1 \\ 748 & 9.0\end{array}$

6.6
Table 1 Basic socio-demographic characteristics of mothers' with children 0-5 years of age, Sri Lanka 2016/2017 $(n=8313)$ (Continued)

\begin{tabular}{lll}
\hline Characteristic & Number & Percentage \\
\hline Hindu & 1284 & 18.1 \\
Islam & 815 & 11.5 \\
Roman Catholic & 508 & 7.2 \\
Other Christian & 92 & 1.3 \\
Other & 3 & .0
\end{tabular}

Nationality $(n=7077)$

Sinhala

$4648 \quad 65.7$

Sri Lanka Tamil

Indian Tamil

3.0

Sri Lanka Moor

10.5

Muslim

0.2

Malay

Maternal working state $(n=7187)$

Non-working

77.0

Working

Father's working state $(n=6097)$

Non-working

1.8

Working

98.2

Maternal education $(n=7187)$

Primary or no schooling

5.0

6-10

44.0

Passed OL

16.3

Passed AL

29.1

Degree or higher

5.6

Father's education $(n=6097)$

Primary or no schooling

8.2

6-11

49.4

$\mathrm{OL}$

16.3

$\mathrm{AL}$

21.9

Degree or higher

Mother's age at delivery (years) $n=7140$

$\begin{array}{lll}15-19 & 460 & 6.4 \\ 20-34 & 5372 & 75.2 \\ 35-49 & 1308 & 18.3\end{array}$

Household wealth index

$(n=7077)$

Poorest

1760

24.9

Poorer

20.7

Middle

19.2

Richer

19.2

Richest

16.0 
Table 1 Basic socio-demographic characteristics of mothers' with children 0-5 years of age, Sri Lanka 2016/2017 $(n=8313)$ (Continued)

$\begin{aligned} & \text { Characteristic } \\ & \text { Healthcare decisions making } \\ & (n=7187)\end{aligned}$
Mother involved
Mother not involved
Other household decision
making ( $n=7187)$
Mother involved
Mother not involved
Having access to any media
frequently ( $\boldsymbol{n}=\mathbf{6 8 6 9 )}$
Yes
No

Birth order

First born
Second or Third
Fourth or fifth
Six or more
Sex of child
Male
Female

Age of child (years)

$0-1$
$1-2$
$2-3$
$3-4$
$4-5$
$5+$
Place of birth
Government hospital
Private hospital
Other

\section{Place of birth}

Institutional
Non-institutional
Mode of delivery
Normal vaginal delivery
Caesarean section
Other

Antenatal care $(n=7187)$

Received

Not

Registered by ${ }^{\mathrm{P}} \mathrm{PHM}(\boldsymbol{n}=\mathbf{7 1 1 8})$

$$
\text { Yes }
$$

No

\section{Number} Percentage

\section{6}

1051

85.4

14.6

\section{2}

1715

76.1

23.9

\section{4}

765

88.9

11.1

3214

4581

38.7

55.1

475

5.7

0.5

43

4279

4034

1500

1560

1708

1673

1709

71
Table 1 Basic socio-demographic characteristics of mothers' with children 0-5 years of age, Sri Lanka 2016/2017 $(n=8313)$ (Continued)

\begin{tabular}{|c|c|c|}
\hline Characteristic & Number & Percentage \\
\hline \multicolumn{3}{|l|}{$\begin{array}{l}\text { Antenatal clinic frequency } \\
(n=7118)\end{array}$} \\
\hline More than or equal four visits & 7078 & 99.4 \\
\hline Less than four visits & 40 & 0.6 \\
\hline \multicolumn{3}{|l|}{$\begin{array}{l}\text { Antenatal tetanus toxoid } \\
(n=7072)\end{array}$} \\
\hline Yes & 6831 & 96.6 \\
\hline No & 241 & 3.4 \\
\hline \multicolumn{3}{|c|}{$\begin{array}{l}\text { Antenatal awareness on where } \\
\text { to go with complications }(n=7094)\end{array}$} \\
\hline Yes & 6540 & 92.2 \\
\hline No & 554 & 7.8 \\
\hline \multicolumn{3}{|l|}{$\begin{array}{l}\text { Antenatal home visits by } \\
{ }^{\operatorname{a}} \operatorname{PHM}(n=7187)\end{array}$} \\
\hline Yes & 6510 & 90.6 \\
\hline No & 677 & 9.4 \\
\hline \multicolumn{3}{|l|}{$\begin{array}{l}\text { Number of antenatal home visits } \\
\text { by }{ }^{\mathrm{a}} \mathrm{PHM}(n=6510)\end{array}$} \\
\hline 1 & 587 & 9.0 \\
\hline 2 & 854 & 13.1 \\
\hline 3 & 1300 & 20.0 \\
\hline$>=4$ & 3770 & 57.9 \\
\hline
\end{tabular}

to perceived hardship of field works comparing to other sophisticated job opportunities for similar education qualifications.

The reasons for low coverage may be due to some maternal factors such as unavailability at home in PN period. Sri Lankan women, especially primi-mothers, prefer to go to their parents after delivery $[25,26]$. In such a situation, the care should be given from the second area PHM. There may be communication gaps. Excessive workload of PHM may be associated with low coverage [27]. Further analysis is needed to understand the factors that contribute to low coverage of the field related PNC.

The finding that more than three fourth of PN mothers have received FPNC as recommended by WHO was slightly higher compared to the reports from other countries in the South East Asian region. Nepal DHS 2016 analysis got PN check-up within 7 days of delivery as $54.5 \%$ [28]. Complete utilization of PNC in Nepal is around $22 \%$, with the definition of three PNC within 7 days of delivery [29]. Three PN visits were less as 17.5\% in another study from Nepal, Chitwan [30]. Similarly a study conducted in Bangladesh, taken PNC more than three times in PP period was 29\% [31]. Sri Lankan 
Table 2 Post-partum care indicators among mothers with children less than 5 years of age, Sri Lanka, 2016/2017

\begin{tabular}{|c|c|c|c|c|}
\hline & Indicator & Sample size & Number & Percentage $\%$ \\
\hline 1 & Received Postnatal care at facility at least $24 \mathrm{~h}$ & 8260 & 8118 & 98.3 \\
\hline 2 & Received Postnatal check-up within one hour of delivery & 7647 & 6125 & 80.1 \\
\hline 3 & Received Postnatal check-up within $4 \mathrm{~h}$ of delivery & 7526 & 7325 & 97.3 \\
\hline 4 & Received Postnatal check-up within $24 \mathrm{~h}$ of delivery & 7647 & 7526 & 98.4 \\
\hline 5 & Received Postnatal check-up by a skilled personal & 7647 & 7607 & 99.5 \\
\hline 6 & Received Postnatal check-up before discharge by a doctor & 7988 & 7855 & 98.3 \\
\hline 7 & Received post-partum home visits by PMH & 8313 & 7933 & 95.4 \\
\hline 8 & Received first post-partum home visit by PHM within 5 days of delivery & 6646 & 3935 & 59.2 \\
\hline 9 & Received first post-partum home visit by PHM within 10 days of delivery & 6646 & 5687 & 85.6 \\
\hline 10 & Received at least 4 post-partum home visits by PHM & 6595 & 1712 & 26.0 \\
\hline 11 & Received at least 3 post-partum home visits by PHM & 6595 & 3712 & 56.3 \\
\hline 12 & Received at least 2 post-partum home visits by PHM & 6595 & 5546 & 84.1 \\
\hline 13 & PHM has made aware of mothers at home visits regarding the available services in postnatal care & 6757 & 6333 & 93.7 \\
\hline 14 & Attended Postnatal clinic conducted by $\mathrm{MOOH}$ & 7187 & 5606 & 78.0 \\
\hline 15 & Postnatal mother had a check by doctor at the postnatal clinic & 5606 & 4410 & 78.7 \\
\hline 16 & Postnatal baby had a check by doctor at the postnatal clinic & 5606 & 5399 & 96.3 \\
\hline 17 & Received additional 3 check-ups within 6 weeks of delivery: in the field or clinic setup. & & & \\
\hline 18 & Received FPNC according to WHO guideline & 6641 & 5104 & 76.9 \\
\hline 19 & Received FPNC according to FHB guideline. & 6220 & 860 & 13.8 \\
\hline 20 & Received field related FPNC care according to FHB guideline. & 6468 & 926 & 14.3 \\
\hline 21 & Received within the institution FPNC care according to FHB guideline. & 7634 & 7264 & 95.2 \\
\hline
\end{tabular}

PHM public health midwife, $M O O H$ Medical officers of health, FPNC full postnatal care, FHB Family Health Bureau

healthcare system may be more advanced than other regional countries. Socio-demographic variation between different countries as well as within the same country may be another reason for the difference.

Countries in African region showed relatively less coverage. In Nigeria, being the definition of FNAC same, it was $74 \%$ in urban areas and $61 \%$ in rural areas [32]. In Ethiopia, it was differing as $28 \%$ [33] (only three contacts in PP period), 57.5\% [34] and 67\% [35] with different study settings and different definitions of postnatal care coverage. In SSA countries, the median percentage of women who reported receiving a PN check was 71.7\%, ranging from $26.6 \%$ in Swaziland to $94.4 \%$ in Burkina Faso [5]. In Malawi, 48\% PN women had a check by skilled healthcare worker [36]. These differences may be due to the variation of socio-demographic factors as well as time gap of studies. There may be more improvement in MNH services with modern technology and facilities in recent developments in all countries.

The above findings of associated factors show a close linkage between some maternal characteristics, antenatal care and PNC. Getting antenatal home visits by PHM has increased receiving FPNC among mothers. This finding was in agreement with a study from India, which detected that contacts with health worker during pregnancy increased utilization on postnatal care [34]. The fact that the mother was in close relationship with PHM who had home visits would explain the above finding. In antenatal home visits, PHM assesses mother's health as well as other social determinants of health. She gets an opportunity to provide overall knowledge that improve attitude and practices individually to mothers in home visits [11].

In our analysis, we detected that mothers receiving knowledge about antenatal complications and available services for complications from ANC had received more FPNC. However, the finding was based on a single question used in SLDHS regarding awareness on antenatal complications. Limenehi has found that awareness about maternal complication improves PNC [37]. Receiving antenatal care showed positive association with receiving PNC in several other studies. Uptake of recommended number of ANC visits was a factor which increases PNC $[6,36,38,39]$. A timely first ANC visit and receiving the adequate number of tetanus injections showed association with PNC as detected by Khaki [36]. Not only are the visits, the content of care received during ANC detected as important [39]. Even though some studies elicited a positive association between, receiving recommended number of antenatal clinic visits and PNC, we 
Table 3 Association of receiving full postnatal care according to WHO guidelines with socio-demographic and obstetric care related factors

\begin{tabular}{|c|c|c|c|c|c|}
\hline \multirow[t]{2}{*}{ Variable } & \multicolumn{5}{|c|}{ Receiving FPNC WHO } \\
\hline & No & $\%$ & Crude OR & $95 \% \mathrm{Cl}$ & $P$ value \\
\hline \multicolumn{6}{|l|}{ Socio-demographic factors } \\
\hline \multicolumn{6}{|l|}{ Residence $(n=6542)^{\mathrm{a}}$} \\
\hline Rural & 4021 & 78.1 & 1.337 & $1.168-1.530$ & 0.000 \\
\hline Urban+ Estate & 1015 & 72.8 & & & \\
\hline \multicolumn{6}{|l|}{ Religion $(n=6542)^{a}$} \\
\hline Buddhist & 3270 & 80.4 & 1.652 & $1.470-1.856$ & 0.000 \\
\hline Non-Buddhist & 1766 & 71.3 & & & \\
\hline \multicolumn{6}{|l|}{ Nationality $(n=6542)^{a}$} \\
\hline Sinhala & 3473 & 80.5 & 1.762 & $1.566-1.982$ & 0.000 \\
\hline Non-Sinhala & 1563 & 70.1 & & & \\
\hline \multicolumn{6}{|c|}{ Mother's age at delivery (years) $(n=6600)^{b}$} \\
\hline $20-34$ & 1257 & 77.5 & 1.047 & $0.916-1.197$ & 0.497 \\
\hline Below 20 and above 35 & 3817 & 76.7 & & & \\
\hline \multicolumn{6}{|c|}{ Maternal working state $(n=6641)^{c}$} \\
\hline Working & 1184 & 77.7 & 1.063 & $0.927-1.219$ & 0.379 \\
\hline Non-working & 3920 & 76.6 & & & \\
\hline \multicolumn{6}{|c|}{ Father's working status $(n=5649)^{d}$} \\
\hline Working & 4276 & 77.1 & 1.289 & $0.830-2.002$ & 0.256 \\
\hline Non-working & 73 & 72.3 & & & \\
\hline \multicolumn{6}{|c|}{ Maternal education $(n=6641)^{c}$} \\
\hline AL and above & 1815 & 78.5 & 1.158 & $1.026-1.308$ & 0.018 \\
\hline Up to passed OL & 3289 & 76.0 & & & \\
\hline \multicolumn{6}{|c|}{ Father's education $(n=5649)^{d}$} \\
\hline $\mathrm{AL}$ and above & 1147 & 77.1 & 1.007 & $0.875-1.160$ & 0.918 \\
\hline Up to passed OL & 3202 & 77.0 & & & \\
\hline \multicolumn{6}{|c|}{ Household wealth index quintile $(n=6542)^{e}$} \\
\hline Richer/ Richest & 1824 & 79.0 & 1.199 & $1.061-1.355$ & 0.004 \\
\hline Poorest/ Poorer/ Middle & 3212 & 75.9 & & & \\
\hline \multicolumn{6}{|c|}{ Healthcare decisions making ability $(n=6641)^{c}$} \\
\hline Mother involved & 4373 & 77.0 & 1.058 & $0.901-1.242$ & 0.490 \\
\hline Mother not involved & 731 & 76.0 & & & \\
\hline \multicolumn{6}{|c|}{ Other household decision making ability $(n=6641)^{c}$} \\
\hline Mother involved & 3916 & 77.3 & 1.121 & $0.982-1.279$ & 0.090 \\
\hline Mother not involved & 1188 & 75.3 & & & \\
\hline \multicolumn{6}{|c|}{ Spending decision on father's earning $(n-6641)^{c}$} \\
\hline Mother involved & 3564 & 77.4 & 1.096 & $0.970-1.239$ & 0.142 \\
\hline Mother not involved & 1540 & 75.7 & & & \\
\hline \multicolumn{6}{|c|}{ Maternal access to any media frequently $(n=6363)^{f}$} \\
\hline Yes & 4361 & 77.0 & 0.982 & $0.815-1.185$ & 0.852 \\
\hline No & 543 & 77.4 & & & \\
\hline \multicolumn{6}{|c|}{ Newspaper read by mother frequently $(n=6363)^{g}$} \\
\hline Yes & 1994 & 76.5 & 0.946 & $0.840-1.065$ & 0.356 \\
\hline
\end{tabular}


Table 3 Association of receiving full postnatal care according to WHO guidelines with socio-demographic and obstetric care related factors (Continued)

\begin{tabular}{|c|c|c|c|c|c|}
\hline \multirow[t]{2}{*}{ Variable } & \multicolumn{5}{|c|}{ Receiving FPNC WHO } \\
\hline & No & $\%$ & Crude OR & $95 \% \mathrm{Cl}$ & $P$ value \\
\hline No & 2916 & 77.5 & & & \\
\hline \multicolumn{6}{|c|}{ Watch TV by mother frequently $(n=6635)^{h}$} \\
\hline Yes & 4098 & 76.9 & 1.018 & $0.883-1.175$ & 0.802 \\
\hline No & 1001 & 76.6 & & & \\
\hline \multicolumn{6}{|c|}{ Listening radio frequently $(n=6641)^{i}$} \\
\hline Yes & 2455 & 77.1 & 1.030 & $0.919-1.154$ & 0.613 \\
\hline No & 2649 & 76.6 & & & \\
\hline \multicolumn{6}{|c|}{ Mother own mobile phone $(n=6641)^{i}$} \\
\hline Yes & 4096 & 77.6 & 1.225 & $1.068-1.405$ & 0.004 \\
\hline No & 1008 & 73.9 & & & \\
\hline \multicolumn{6}{|c|}{ Mother own bank account $(n=6641)^{i}$} \\
\hline Yes & 4242 & 77.6 & 1.258 & $1.090-1.454$ & 0.002 \\
\hline No & 862 & 73.4 & & & \\
\hline \multicolumn{6}{|c|}{ Mother use internet ever $(n=6641)^{i}$} \\
\hline Yes & 1033 & 76.0 & 0.943 & $0.819-1.084$ & 0.408 \\
\hline No & 4071 & 77.1 & & & \\
\hline \multicolumn{6}{|l|}{ Obstetric care related factors } \\
\hline \multicolumn{6}{|c|}{ Antenatal Registration by PHM $(n=6587)^{j}$} \\
\hline Yes & 5018 & 76.9 & 0.901 & $0.487-1.668$ & 0.740 \\
\hline No & 48 & 78.7 & & & \\
\hline \multicolumn{6}{|c|}{ Antenatal clinic care $(n=6641)^{\mathrm{k}}$} \\
\hline Received & 5066 & 76.9 & 1.402 & $0.780-2.522$ & 0.257 \\
\hline Not received & 38 & 70.4 & & & \\
\hline \multicolumn{6}{|c|}{$\begin{array}{l}\text { Antenatal clinic made awareness on } \\
\text { complication and services }(n=6573)^{\prime}\end{array}$} \\
\hline Yes & 4736 & 77.9 & 1.917 & $1.579-2.329$ & $<0.001$ \\
\hline No & 320 & 64.8 & & & \\
\hline \multicolumn{6}{|c|}{$\begin{array}{l}\text { Antenatal clinic attendance frequency } \\
(n=6587)^{\mathrm{m}}\end{array}$} \\
\hline 4 or more & 5046 & 77.0 & 2.344 & $1.181-4.652$ & 0.012 \\
\hline Less than 4 & 20 & 58.8 & & & \\
\hline \multicolumn{6}{|c|}{ Antenatal tetanus toxoid $(n=6552)^{n}$} \\
\hline Received & 4882 & 77.1 & 1.169 & $0.857-1.593$ & 0.323 \\
\hline Not received & 161 & 74.2 & & & \\
\hline \multicolumn{6}{|c|}{ Antenatal home visits by PHM $(n=6641)^{\circ}$} \\
\hline Yes & 4716 & 78.1 & 1.966 & $1.646-2.348$ & $<0.001$ \\
\hline No & 388 & 64.5 & & & \\
\hline \multicolumn{6}{|l|}{ Place of birth } \\
\hline Institution & 5104 & 76.9 & Not calculated & & \\
\hline Non-institution & 0 & 0 & & & \\
\hline \multicolumn{6}{|c|}{ Mode of delivery $(n=6641)^{\circ}$} \\
\hline Normal vaginal delivery & 3516 & 76.0 & 0.852 & $0.751-0.966$ & 0.013 \\
\hline Other & 1588 & 78.8 & & & \\
\hline
\end{tabular}


Table 3 Association of receiving full postnatal care according to WHO guidelines with socio-demographic and obstetric care related factors (Continued)

\begin{tabular}{|c|c|c|c|c|c|}
\hline \multirow[t]{2}{*}{ Variable } & \multicolumn{5}{|c|}{ Receiving FPNC WHO } \\
\hline & No & $\%$ & Crude OR & $95 \% \mathrm{Cl}$ & $P$ value \\
\hline \multicolumn{6}{|c|}{ Birth order $(n=6641)^{\circ}$} \\
\hline First born & 1799 & 75.9 & 0.923 & $0.820-1.039$ & 0.187 \\
\hline Others & 3305 & 77.4 & & & \\
\hline \multicolumn{6}{|c|}{ Sex of child $(n=6641)^{\circ}$} \\
\hline Male & 2650 & 77.9 & 1.124 & $1.003-1.260$ & 0.044 \\
\hline Female & 2454 & 75.8 & & & \\
\hline
\end{tabular}

FPNC full postnatal care, PHM Public health midwife

$\mathrm{a}-\mathrm{O}=$ missing values, ${ }^{\mathrm{a}} 506 ;{ }^{\mathrm{b}} 1526 ;{ }^{\mathrm{c}} 1537 ;{ }^{\mathrm{d}} 23 ;{ }^{\mathrm{e}} 606 ;{ }^{\mathrm{f}} 1459 ;{ }^{\mathrm{g}} 1453 ;{ }^{\mathrm{h}} 1536 ;{ }^{\mathrm{i}} 1537 ;{ }^{\mathrm{j}} 1521 ;{ }^{\mathrm{k}} 1537 ;{ }^{\mathrm{l}} 1517 ;{ }^{\mathrm{m}} 1521 ;{ }^{\mathrm{n}} 1509 ;{ }^{\mathrm{o}} 1537$

were unable to elicit it here $[6,36,38,39]$. Similarly, several studies found that content of care received and components of ANC were associated with PNC attendance [40]. Here we could not elicit it due to the fact that almost all ANC related components have achieved coverage of more than $99 \%$.

Our analysis found that mothers with own mobile phones received more PNC. This could be due to women who have mobile phones may have more autonomy and can efficiently contact health staff. The results are consistence with findings that women's phone ownership and usage is generally associated with better reproductive care indicators [41, 42]. Using m-health interventions to strengthen postnatal care has proven benefits [43, 44]. The assessment here was only covers one question in SLDHS regarding the ownership of a mobile phone, which may need further information on usage for further inferences.

The current analysis shows that mothers from rural areas are less likely to receive FPNC compared to mothers in urban areas. This is similar to what was reported in other studies in Ethiopia [35, 38] Uganda [6], Malawi [36] and Indonesia [45] as high postnatal access in urban mothers. Many factors may contribute to the results. Health care facilities are more concentrated in urban areas [46]. More educated and financially stable

Table 4 Association of receiving full postnatal care according to WHO guidelines with socio-demographic and obstetric care related factors

\begin{tabular}{|c|c|c|c|c|}
\hline & Variable & AOR & $95 \% \mathrm{Cl}$ & $P$ value \\
\hline \multirow[t]{3}{*}{1} & Residence & & & \\
\hline & Rural & 0.697 & $0.522-0.933$ & 0.015 \\
\hline & Estate & 0.830 & $0.639-1.078$ & 0.163 \\
\hline 2 & Religion: Buddhist & 0.853 & $0.610-1.193$ & 0.353 \\
\hline 3 & Nationality: Sinhala & 1.892 & $1.346-2.662$ & $<0.001$ \\
\hline \multirow[t]{3}{*}{4} & Mother's age at delivery (years) & & & \\
\hline & $20-34$ & 0.724 & $0.541-0.968$ & 0.029 \\
\hline & Above 35 & 0.851 & $0.721-1.003$ & 0.054 \\
\hline 5 & Maternal education: AL or above & 1.006 & $0.873-1.158$ & 0.936 \\
\hline 6 & Household wealth index quintile & 1.069 & $0.925-1.237$ & 0.367 \\
\hline 7 & Mothers involve in household decision making ability & 1.041 & $0.898-1.207$ & 0.590 \\
\hline 8 & Mothers involve in spending decision on father's earning & 1.039 & $0.906-1.102$ & 0.586 \\
\hline 9 & Mother own mobile phone & 1.188 & $1.020-1.384$ & 0.027 \\
\hline 10 & Mother own bank account & 1.037 & $0.884-1.217$ & 0.655 \\
\hline 11 & Antenatal clinic made awareness on complication and services & 1.562 & $1.273-1.916$ & $<0.001$ \\
\hline 12 & Antenatal clinic attendance frequency 4 or more & 1.635 & $0.792-3.376$ & 0.184 \\
\hline 13 & Antenatal home visits by $\mathrm{PHM}^{*}$ & 1.985 & $1.648-2.392$ & 0.000 \\
\hline 14 & Normal vaginal delivery & 0.924 & $0.808-1.056$ & 0.245 \\
\hline 15 & First born child & 0.955 & $0.834-1.093$ & 0.505 \\
\hline
\end{tabular}


women may live in urban areas, which may enhance the receiving healthcare. Contradictory finding detected in Nepal DHS 2016 as urban area mothers have less PNC [28].

Our finding, that older maternal age was associated with less FPNC, is tallying with Rwanda mothers [47]. Older women may have thought that PNC as not necessary with their previous experiences. Younger women less than 20 years of age are considered as high risk due to teenage years and have drawn more attention in field and hospital level in SriLanka. This may be an explanation for the above result. In contrast to our findings, Khaki detected older age as receiving more PNC in Malawian women [36].

The other factor which detected strong positive association in several studies around the globe was the institutional delivery $[6,28,34,48]$. We could not demonstrate that association due to the fact that more than $99 \%$ deliveries occurred in institutions. Mode of delivery being caesarian received more $\mathrm{PNC}$, which could not be detected with our analysis [5, 33, 36, 38].

The main strength of this study is that it is based on a nationally representative sample. SLDHS collect quality data with rigorous methodology with the involvement of experienced staff. 2016 survey included all nine provinces in the country including Northern Province which was excluded in previous surveys due to conflict situation there. Data were collected tallying with pregnancy record whenever available. Therefore, the recall bias may be minimized. The major limitation is the cross-sectional nature of the SLDHS survey, which means that only associations could be detected between the variables, not causality. Another limitation is that due to secondary data, some important associated variables may have missed such as family support, distance to health facilities, availability of healthcare personals, etc. Actual figure of receiving FPNC may be higher than the analyzed one. SLDHS 2016 has not collected data on private sector contacts in PN period. It collected data on PN clinic visit conducted by $\mathrm{MOOH}$ only. Private checkups with a consultant or a general practitioner are prevailing in some areas of the country. The study has included mothers who gave birth on last 5 years. Therefore there might be a possibility of some recall bias.

\section{Conclusion}

Almost all PN mothers in Sri Lanka received institutional PN care for more than $24 \mathrm{~h}$. The coverage of receiving FPNC was found to be higher than other countries in the region. Nevertheless, the distribution of receiving care among different socio-economical groups are unequal. Some vulnerable groups such as mothers reside in rural areas; mothers with older maternal age in the country are at risk of being left behind. Healthcare decision makers should target these groups with different strategies than normal routine. Inequality in receiving care among women of different places of residence need to be considered at the policy making level. Future programme efforts should focus on ensuring the equal distribution of resources to promote the equity of care. Strategies that aim to improve PNC should target improvement of non-health factors.

\section{Abbreviations \\ ANC: Antenatal clinic; AOR: Adjusted odds ratios; Cl: Confidence interval; DCS: Department of census and statistics; FHB: Family Health Bureau; FPNC: Full postnatal care; LMIC: Lower and middle income countries; MCH: Maternal and child health; MLR: Multiple logistic regression; $\mathrm{MNH}$ : Maternal and neonatal health; $\mathrm{MOOH}$ : Medical officers of Health; OR: Odds ratios; PHM: Public health midwife; PN: Postnatal; PNC: Postnatal care; PSU: Primary sampling units; SLDHS: Sri Lanka Demographic and Health Survey; SPSS: Statistical Package for Social Sciences; SSA: Sub-Saharan Africa; WHO: World Health Organization; WI: Wealth Index}

\section{Acknowledgements}

Staff of School of Public Health, the University of Queensland and the Staff of the Department of census and statistics in SriLanka.

\section{Authors' contributions}

UAPP, UA and YA conceived, coordinated and designed the study. UAPP analysed the data wrote the first draft of the manuscript. UAPP, UA and YA interpreted the data and contributed the final writing of the manuscript. All authors read and approved the final manuscript.

\section{Authors' information}

UAPP is a visiting research fellow attached to the School of Public Health, The University of Queensland: UA is a Consultant Community Dentistry, Ministry of Health, Colombo, Sri Lanka and YA is a senior lecturer in Global Health in the School of Public Health, The University of Queensland.

\section{Funding}

No funding was received for this work.

\section{Availability of data and materials}

2016 Sri Lanka Demographic Health Survey dataset is not in the public domain and is a property of the Department of Census and Statistics-Sri Lanka. Additional information and the dataset can be obtained from the Department of Census and Statistics, "Sankyana Mandiraya", 306/71, Polduwa Road, Battaramulla, Sri Lanka, Telephone: +94 112147000 and +94 11 2147400, Email: information@statistics.gov.lk,

\section{Declarations}

Ethics approval and consent to participate

The Sri Lanka Demographic and Health Survey obtained written informed consent from all the participants during the data collection. The survey secured ethical clearance from SriLanka Medical Association- Ethics review. committee. All methods were performed in accordance with the relevant guidelines and regulations (Declaration of Helsinki). Permission was obtained to analyse this data from the Department of Census and Statistics in Sri Lanka.

Consent for publication

Not applicable.

Competing interests

The authors declare that they have no competing interests. 
Received: 9 December 2020 Accepted: 30 March 2021

\section{Published online: 13 April 2021}

\section{References}

1. WHO Technical Consultation on postpartum and postnatal care. Geneva: World Health Organization; 2010

2. Li XF, Fortney JA, Kotelchuck M, Glover LH. The postpartum period: the key to maternal mortality. Int J Gynecol Obstet. 1996;54(1):1-10. https://doi. org/10.1016/0020-7292(96)02667-7.

3. Merdad L, Ali MM. Timing of maternal death: levels, trends, and ecological correlates using sibling data from 34 sub-Saharan African countries. Plos One. 2018;13(1):e0189416. https://doi.org/10.1371/journal.pone.0189416.

4. Newborns: improving survival and well-being WHO 2020. Available from: https://www.who.int/news-room/fact-sheets/detail/newborns-reducingmortality. Accessed 20 Sept 2020

5. Benova L, Owolabi O, Radovich E, Wong KLM, Macleod D, Langlois EV, et al. Provision of postpartum care to women giving birth in health facilities in sub-Saharan Africa: a cross-sectional study using demographic and health survey data from 33 countries. Plos Med. 2019;16(10):e1002943. https://doi org/10.1371/journal.pmed.1002943.

6. Ndugga P, Namiyonga NK, Sebuwufu D. Determinants of early postnatal care attendance in Uganda: further analysis of the 2016 demographic and health survey. Rockville: ICF; 2019.

7. Mon A, Phyu M, Thinkhamrop W, Thinkhamrop B. Utilization of full postnatal care services among rural Myanmar women and its determinants: a crosssectional study [version 1; peer review: 3 approved]. F1000 Research, 2018; 7(1167).

8. Tracking Progress towards Universal Coverage for Reproductive, Newborn and Child Health. Washington, DC United Nations Children's Fund (UNICEF) and the World Health Organization (WHO) 2017.

9. Tessema ZT, Yazachew L, Tesema GA, Teshale AB. Determinants of postnatal care utilization in sub-Saharan Africa: a meta and multilevel analysis of data from 36 sub-Saharan countries. Ital J Pediatr. 2020;46(1):175. https://doi. org/10.1186/s13052-020-00944-y.

10. WHO recommendations on Postnatal care of the mother and newborn2013. Geneva: World Health Organization; 2014.

11. Maternal care package, a guide to field healthcare workers: Family Health Bureau, Ministry of Health; 2011.

12. NICE guideline 2020. Available from: https://www.nice.org.uk/guidance/cg3 7. Accessed 28.08.2020.

13. ACOG Committee Opinion No. 736: optimizing postpartum care. Obstetrics and gynecology. 2018;131(5):e140-e50. Sri Lanka: Family Health Bureau, Ministry of Health 2020.

14. Annual Report of the Family Health Bureau, 2018 ; Family Health Bureau, Ministry of health; 2019.

15. Pathmanathan I, Liljestrand J, Martins J, Rajapaksa L, Lissner C, De Silva A, et al. Investing in maternal health : learning from Malaysia and Sri Lanka. Washington, DC: World Bank; 2003.

16. Senanayake H, Goonewardene M, Ranatunga A, Hattotuwa R, Amarasekera S, Amarasinghe I. Achieving Millennium Development Goals 4 and 5 in Sri Lanka. BJOG. 2011;118(Suppl 2):78-87. https://doi.org/10.1111/j.1471-0528.2 011.03115.x.

17. Haththotuwa R, Senanayake L, Senarath U, Attygalle D. Models of care that have reduced maternal mortality and morbidity in Sri Lanka. Int J Gynecol Obstet. 2012;119(S1):S45-S9. https://doi.org/10.1016/j.jjgo.2012.03.016.

18. Wickramasinghe SA, Gunathunga MW, Hemachandra DKNN. Client perceived quality of the postnatal care provided by public sector specialized care institutions following a normal vaginal delivery in Sri Lanka: a cross sectional study. BMC Pregnancy Childbirth. 2019;19(1):485.

19. Jayasinghe $C$, Abeysena $C$. Maternal satisfaction on postnatal and neonatal care of babies treated for neonatal sepsis in secondary and tertiary care hospitals of a district in Sri Lanka. J Coll Commun Phys Sri Lanka. 2020;26(1): 17-28. https://doi.org/10.4038/jccpsl.v26i1.8209.

20. Department of Census and Statistics (DCS) and Ministry of Health, Nutrition and Indigenous Medicine, Sri Lanka Demographic and Health Survey 2016 Department of Census and Statistics (DCS) and Ministry of Health, Nutrition and Indigenous Medicine, 2017.

21. Hjelm L, Mathiassen A, Miller D, Wadhwa A. Creation of wealth index World food programme; 2017.

22. Annual Report of the Family Health Bureau, 2016. Sri Lanka Family Health Bureau, Ministry of health; 2018.
23. Annual Report of the Family Health Bureau, 2017. Sri Lanka: Family Health Bureau, Ministry of health; 2019.

24. World Health Organization ROfS-EA, editor Every newborn action plan and postnatal care of mother and newborn: report of a regional meeting, Colombo, Sri Lanka, 11-13 November 20142015 2015-06; New Delhi: WHO Regional Office for South-East Asia.

25. De Silva WI. Puerperal morbidity: a neglected area of maternal health in Sri Lanka. Soc Biol. 1998;45(3-4):223-45. https://doi.org/10.1080/19485565.1998. 9988975.

26. Paranavitana R. Some Customs and Superstitions Associated with the Childbirth in Sri Lankan Sinhalese Society; 2008.

27. Sri L, Saukhya Posana ha Subhasadhana A, World Health O. Report of the external review of maternal and newborn health Sri Lanka: 24th September, 2007 to 12 th October, 20072007.

28. Aryal K, Sharma S, Khanal M, Bista B, Sharma S, Kafle S, et al. Maternal Health Care in Nepal: Trends and Determinants. DHS Further Analysis Reports No. 118. Rockville: ICF; 2019.

29. Chhetri S, Shah R, Rajbanshi L. Factors associated with utilization of complete postnatal Care Service in Baglung Municipality, Nepal. Int J Reprod Med. 2020;2020:2892751.

30. Shrestha N, Tiwari B, Piryani S, Khanal G. Postnatal care services utilization in Bharatpur metropolitan city, Chitwan, Nepal. J Chitwan Med Coll. 2019;9(29): 43-50. https://doi.org/10.3126/jcmc.v9i3.25781.

31. Nayan S, Begum N, Abid M, Rahman S, Rajib A, Farzana N, et al. Utilization of postnatal care services among the rural women in Bangladesh. Northern Int Med Coll J. 2017;8(2):208-12. https://doi.org/10.3329/nimcj.v8i2.32551.

32. Igboanusi CJ-C, Sabitu K, Gobir A, Nmadu AG, Joshua I. Factors Affecting the Utilization of Postnatal Care Services in Primary Health Care Facilities in Urban and Rural Settlements in Kaduna State, North-western Nigeria. Am J Publ Health Res. 2019;7:111-17.

33. Akibu M, Tsegaye W, Megersa T, Nurgi S. Prevalence and determinants of complete postnatal care service utilization in northern Shoa, Ethiopia. J Pregnancy. 2018;2018:8625437.

34. Wudineh KG, Nigusie AA, Gesese SS, Tesfu AA, Beyene FY. Postnatal care service utilization and associated factors among women who gave birth in Debretabour town, North West Ethiopia: a community- based crosssectional study. BMC Pregnancy Childbirth. 2018;18(1):508.

35. Tesfahun F, Worku W, Mazengiya F, Kifle M. Knowledge, perception and utilization of postnatal care of mothers in Gondar Zuria District, Ethiopia: a cross-sectional study. Matern Child Health J. 2014;18(10):2341-51. https:// doi.org/10.1007/s10995-014-1474-3.

36. Khaki JJ, Sithole L. Factors associated with the utilization of postnatal care services among Malawian women. Malawi Med J. 2019;31(1):2-11. https:// doi.org/10.4314/mmj.v31i1.2.

37. Limenih MA, Endale ZM, Dachew BA. Postnatal Care Service Utilization and Associated Factors among Women Who Gave Birth in the Last 12 Months prior to the Study in Debre Markos Town, Northwestern Ethiopia: A Community-Based Cross-Sectional Study. Int J Reprod Med. 2016;2016:7095352.

38. Berhe A, Bayray A, Berhe Y, Teklu A, Desta A, Araya T, et al. Determinants of postnatal care utilization in Tigray, northern Ethiopia: a community based cross-sectional study. Plos One. 2019;14(8):e0221161. https://doi.org/10.1371/ journal.pone.0221161.

39. Fekadu GA, Ambaw F, Kidanie SA. Facility delivery and postnatal care services use among mothers who attended four or more antenatal care visits in Ethiopia: further analysis of the 2016 demographic and health survey. BMC Pregnancy Childbirth. 2019;19(1):64.

40. Fekadu GA, Kassa GM, Berhe AK, Muche AA, Katiso NA. The effect of antenatal care on use of institutional delivery service and postnatal care in Ethiopia: a systematic review and meta-analysis. BMC Health Serv Res. 2018; 18(1):577. https://doi.org/10.1186/s12913-018-3370-9.

41. LeFevre AE, Shah N, Bashingwa JJH, George AS, Mohan D. Does women's mobile phone ownership matter for health? Evidence from 15 countries. BM Glob Health. 2020;5(5):e002524. https://doi.org/10.1136/bmjgh-2020-002524.

42. Tang S, Ghose B, Hoque MR, Hao G, Yaya S. Women using Mobile phones for health communication are more likely to use prenatal and postnatal Services in Bangladesh: cross-sectional study. JMIR Mhealth Uhealth. Available from: http://europepmc.org/abstract/MED/30816850. Accessed 20 Sept 2020.

43. Mbuthia F, Reid M, Fichardt A. mHealth communication to strengthen postnatal care in rural areas: a systematic review. BMC Pregnancy Childbirth. 2019;19(1):406. https://doi.org/10.1186/s12884-019-2531-0. 
44. Olajubu AO, Fajemilehin BR, Olajubu TO, Afolabi BS. Effectiveness of a mobile health intervention on uptake of recommended postnatal care services in Nigeria. Plos One. 2020;15(9):e0238911. https://doi.org/10.1371/ journal.pone.0238911.

45. Titaley CR, Dibley MJ, Roberts CL. Factors associated with non-utilisation of postnatal care services in Indonesia. J Epidemiol Community Health. 2009; 63(10):827-31. https://doi.org/10.1136/jech.2008.081604.

46. Fernando D. Health care systems in transition III. Sri Lanka, part I. an overview of Sri Lanka's health care system. J Public Health Med. 2000;22(1): 14-20. https://doi.org/10.1093/pubmed/22.1.14.

47. Rwabufigiri BN, Mukamurigo J, Thomson DR, Hedt-Gautier BL, Semasaka JPS. Factors associated with postnatal care utilisation in Rwanda: a secondary analysis of 2010 demographic and health survey data. BMC Pregnancy Childbirth. 2016;16(1):122. https://doi.org/10.1186/s12884-016-0913-0.

48. Singh R, Neogi SB, Hazra A, Irani L, Ruducha J, Ahmad D, et al. Utilization of maternal health services and its determinants: a crosssectional study among women in rural Uttar Pradesh, India. J Health Popul Nutr. 2019;38(1):13

\section{Publisher's Note}

Springer Nature remains neutral with regard to jurisdictional claims in published maps and institutional affiliations.

Ready to submit your research? Choose BMC and benefit from:

- fast, convenient online submission

- thorough peer review by experienced researchers in your field

- rapid publication on acceptance

- support for research data, including large and complex data types

- gold Open Access which fosters wider collaboration and increased citations

- maximum visibility for your research: over $100 \mathrm{M}$ website views per year

At BMC, research is always in progress.

Learn more biomedcentral.com/submissions 